Acta Crystallographica Section B

Structural

Science

ISSN 0108-7681

\section{addenda and errata}

\title{
Order-disorder transition in monoclinic
} sulfur: a precise structural study by highresolution neutron powder diffraction. Corrigendum

W. I. F. David, ${ }^{a}$ R. M. Ibberson, ${ }^{a *}$ S. F. J. Cox ${ }^{\mathrm{a}}$ and P. T. Wood $^{b} \neq$

aISIS Facility, CCLRC, Rutherford Appleton Laboratory, Chilton, Didcot, Oxfordshire OX11 0QX, England, and ${ }^{\mathbf{b}}$ School of Chemical Sciences, University of East Anglia, Norwich, Norfolk NR4 7TJ, England

₹ Present address: The University Chemical Laboratory, University of Cambridge, Lensfield Road, Cambridge CB2 1EW, England.

Correspondence e-mail: r.m.ibberson@rl.ac.uk

Revised lattice parameters for Table 1 of the paper by David $e t$ al. (2006), Acta Cryst. B62, 953-959, are given.

The lattice constants for $\beta$-sulfur at $100 \mathrm{~K}$ given in Table 1 of the paper by David et al. (2006) are incorrect. Correct values are: $a=$ 10.8027 (1), $b=10.6911$ (1), $c=10.6689$ (1) $\AA$; $\beta=95.7124$ (10) ${ }^{\circ} ;=$ $1226.06(2) \AA^{3}$. Also, the $a$ and $c$ axis labels shown in Fig. 2(a) should be reversed.

\section{References}

David, W. I. F., Ibberson, R. M., Cox, S. F. J. \& Wood, P. T. (2006). Acta Cryst. B62, 953-959. 